\title{
Occurrence and Distribution of Plant-Parasitic Nematodes on Muscadine Grapes in Georgia and North Carolina
}

\author{
Ganpati B. Jagdale, ${ }^{1,+}$ Paul M. Severns, ${ }^{1}$ Phillip M. Brannen, ${ }^{1}$ and William O. Cline ${ }^{2}$ \\ ${ }^{1}$ Department of Plant Pathology, University of Georgia, Athens, GA 30602 \\ ${ }^{2}$ Entomology and Plant Pathology, North Carolina State University, Horticultural Crops Research Station, Castle Hayne, NC 28429
}

Accepted for publication 2 August 2019.

\begin{abstract}
Muscadine grape, Vitis rotundifolia, is native to the southeastern United States, but Georgia (GA) and North Carolina (NC) are the largest North American producers. Plant-parasitic nematodes (PPNs) have become a significant factor affecting the health, quality, production, and maintenance of bunch grapes (V. labrusca, $V$. vinifera), but little is known about muscadine PPNs. A systematic survey was conducted of PPNs infesting eight and 11 muscadine grape vineyards in GA and NC in August and October 2018, respectively. The most frequently detected PPNs across all samples from both states were Helicotylenchus (90\%), Mesocriconema $(72 \%)$, and Xiphinema (58\%). However, 5 Hemicycliophora and $710 \mathrm{Scu}$ tellonema nematodes $/ 100 \mathrm{~cm}^{3}$ of soil were found only in $\mathrm{GA}$,

whereas only 1 Belonolaimus nematode/100 $\mathrm{cm}^{3}$ of soil was found only in NC. Ordination of the nematode communities from the samples collected in GA and NC yielded groupings that aligned with the state of origin. Multivariate tests for group membership indicated that several genera were statistically associated with either NC or GA muscadines, and the PPN communities distinctly differed between states. Because muscadine grapes do not have established nematode thresholds, it is not known whether these nematode species are negatively impacting mature grapes.

Keywords: nematology, small fruits, Helicotylenchus, Mesocriconema, Xiphinema
\end{abstract}

Muscadine grape (Vitis rotundifolia Michx.) is native to the southeastern United States. Georgia (GA) and North Carolina (NC) are the largest producers of these grapes, with over 648 and 526 planted hectares and averages of $\$ 2.7$ and $\$ 2.5$ million farmgate values, respectively (Cline and Fisk 2006; Georgia Crop Reporting Service 2000; USDA 2015). Muscadine grapes are valued for their fresh, sweet, and unique flavor (Krewer and Myers 2017), and in addition to fresh market sales, they are used for making juices, jams, pies, wines, and nutraceuticals that have many health benefits. Muscadines contain a high level of resveratrols, phenols, and antioxidants (Ector et al. 1996; Pastrana-Bonilla et al. 2003; Percival et al. 2002) that are known to help in fighting cardiovascular diseases and cancer-causing agents (Olas and Wachowicz 2005; Signorelli and Ghidoni 2005). Although muscadine grapes are fairly resistant to different diseases and insect pests compared with bunch grapes (Vitis labrusca L., Vitis vinifera L.), they are attacked by a variety of diseases such as angular leaf spot (Mycosphaerella angulata Jenkins, 1942), bitter rot (Greeneria uvicola Berk. and M. A. Curtis 1887, syn. Melanconium fuligineum Scribn. and Viala Cavara 1888), powdery mildew (Uncinula necator Schwein, Burrill), ripe rot (Glomerella cingulata [Stoneman] Spaulding and von Schrenk), Macrophoma rot (Botryosphaeria dothidea Mough.: Fr. [Ces. \& De Not]), black rot (Guignardia bidwellii [Ellis] Viala

${ }^{\dagger}$ Corresponding author: G. B. Jagdale; E-mail: gbjagdal@uga.edu

Funding: The authors thank the Southern Region Small Fruit Consortium for funding.

The author(s) declare no conflict of interest.

(C) 2019 The American Phytopathological Society and Ravaz f. muscadinii Luttrell), Pierce's disease (Xylella fastidiosa Wells, Raju, Hung, Weisburg, Parl and Beemer), and crown gall (Agrobacterium sp.). Diseases and insects (aphids, stink bugs, grape berry moth, grape root borer, flea beetle, and Japanese beetle) can also cause serious damage to grape vines, resulting in reduced yields (Cline et al. 2010).

Plant-parasitic nematodes (PPNs) have become a significant factor affecting the health, quality, production, and maintenance of bunch grapes (V. labrusca, V. vinifera) worldwide (Raski 1988). Major PPNs frequently found associated with bunch grapes include ring (Mesocriconema spp.), root-knot (Meloidogyne spp.), dagger (Xiphinema spp.), and lesion (Pratylenchus spp.) nematodes (Bird and Ransdell 1985; Pinkerton et al. 1999). In GA, a limited survey of predominantly $V$. vinifera conducted during 2002 found six potential PPNs, including root-knot, stubby-root (Paratrichodorus spp.), ring, stunt (Tylenchorhynchus spp.), spiral (Helicotylenchus spp.), and dagger nematodes were associated with $V$. vinifera (Brannen, personal observation). The University of Georgia (UGA) Nematode Diagnostic Laboratory also processed soil samples from seven different bunch grape growers located in seven different counties for the presence of PPNs and confirmed the widespread occurrence and diverse distribution of these six PPN genera associated with unknown species of bunch grapes in GA (Jagdale, personal observation). However, virtually nothing is known about nematode populations in muscadine grapes and their potential for damage over time, especially in replant scenarios.

Limited research has been conducted to establish relationships between various nematodes species and muscadine grapes. For example, Chen et al. (2001) and Lider (1954) reported resistance of muscadine grapes to root-knot nematode and Xiphinema index Thorne and Allen, 1950, respectively. In contrast, Chen et al. 
(2001), speculated that the reduced vine health may be owing to nematodes, because various nematode diagnostic clinics reported the presence of dagger, stubby-root, ring, and spiral nematodes in the soil samples collected from the rhizosphere of $V$. rotundifolia. Over the last 15 years, only four soil samples from muscadine vineyards (four different GA counties) were processed by the UGA Nematode Diagnostic Laboratory. Ring nematodes were present in all samples, but lesion, stubby-root, spiral, and dagger nematodes were present in three samples, root-knot nematodes in two samples, and stunt nematodes in only one sample (Jagdale, personal observation). This suggests that PPNs may be widespread in muscadine grapes, but a more comprehensive sampling effort is necessary to determine whether the muscadine PPN community is similar to that of bunch grape.

\section{Survey of PPNs of Muscadine Grapes in GA and NC}

To better understand the PPN community on muscadine grapes, we sampled the soil of commercial muscadine grape vineyards in GA and NC during August and October 2018, respectively. Working in conjunction with Cooperative Extension agents, PPNs were sampled in eight vineyards planted with mostly 'Carlos' cultivars from seven GA counties (Colquitt, Calhoun, Cook, Grady, Hall, Irwin, and Sumter) and 11 vineyards planted with mostly 'Carlos' cultivars from seven NC counties (Bladen, Duplin, Johnston, New Hanover, Pender, Sampson, and Scotland). In each vineyard, five individual grapevines were randomly selected in a row for soil sampling, and 10 random soil cores (two cores per grapevine) were collected within $\sim 30 \mathrm{~cm}$ of each grapevine trunk using a soil probe $(15 \mathrm{~cm}$ deep $\times 2.5 \mathrm{~cm}$ wide $)$. Soil cores from all five grapevines were combined into one composite sample, and five such composite samples were collected from each vineyard in the study. Each composite sample was placed in a plastic bag and transported back to the Extension Nematology Laboratory, Athens, $\mathrm{GA}$, in coolers. PPNs were collected from a $100-\mathrm{cm}^{3}$ of soil subsample taken from each composite sample as described by Jenkins (1964). Nematodes from each sample were identified to genus and counted at $40 \times$ magnification using an inverted compound microscope. Population size for each genus was calculated as the number of individuals $/ 100 \mathrm{~cm}^{3}$ of soil. Site occurrence for each genus was the total number of samples in which the genus was detected divided by the total number of samples collected in the state (40 and 55 samples collected from GA and NC, respectively), and multiplied by 100 to convert to a percentage. An index of nematode relative abundance was the sum of densities per $100 \mathrm{~cm}^{3}$ of soil divided by the total number of samples in which the nematode genus was detected.

\section{Multivariate Community Analysis}

To visualize how the sampled muscadine nematode communities in GA and NC compare with each other, we used the composite sample data to create an ordination with nonmetric multidimensional scaling (NMS) (Kruskal 1964; McCune and Grace 2002). NMS, like other ordination techniques, is a multivariate analysis using distance matrices to create a set of coordinates for how each sample relates to other samples taking all variables into account. The more distant or closer the points are to each other in ordination space, the more dissimilar or similar the nematode communities in those samples are relative to each other. The primary matrix consisted of the relative abundance of each nematode genus in each sample. Because nematode relative abundance varied by several orders of magnitude between genera within a sample and some genera were not present in a composite sample, we $\ln (x+1)$ transformed the count data to conserve relative abundance and conform to multivariate normality prior to analysis. A second matrix was used to group the samples by the state of origin (GA and NC). We used Gower's distance (250 real runs and 250 randomized runs) for the NMS ordination and conducted the analysis in PCORD 7 (McCune and Mefford 2016).

To determine whether nematode communities on muscadine grapes statistically differed between the samples collected from $\mathrm{NC}$ and GA, we retained the same primary $(\ln [x+1]$ transformed) and secondary matrix in the NMS analysis and tested for group membership with the multirank permutation procedure (MRPP) in PC-ORD 7 (Gower's distance). MRPP is analogous to an ANOVA but for multivariate data. It tests for group membership by comparing the distance values from each sample in the compared groups, calculates a test statistic ( $T$, analogous to a Student's $t$ ), and indexes the effect size though a chance agreement within groups (A statistic). A probability value for between-groups statistical significance is obtained through the $T$ statistic (Mielke and Berry 2001). Because MRPP only tests for group membership, we applied indicator species analysis (Dufrene and Legendre 1997) to the nematode samples to identify which, if any, genera were statistically associated with GA or NC. Indicator species values range from 0 to 100 , with a 100 indicating a perfect indicator species (one that is mutually exclusive to a group and always occurs in the highest relative abundance within that group) and 0 indicating a species that is not affiliated with any group either through occurrence or relative abundance. Probability values were attained through 5,000 randomizations in PC-ORD 7.

\section{Distribution of PPNs on Muscadine in GA and NC}

We found nine PPNs including root-knot, ring, stunt, spiral, stubby-root, lesion, sheath (Hemicycliophora spp.), dagger, and British spiral (Scutellonema spp.) nematodes that were present in muscadine grape vineyards in seven GA counties (Table 1), but their frequencies of occurrence varied among the samples (Table 2). For example, spiral and ring nematodes were present in the highest number of samples (93 and $65 \%$ of samples, respectively), followed by lesion and dagger nematodes in 33 and $28 \%$ of samples, respectively. The other nematodes including stubby-root, root-knot, stunt, sheath, and British spiral nematodes were present only in less than $10 \%$ of soil samples (Table 2). Although the most frequently detected PPNs were spiral $\left(74 / 100 \mathrm{~cm}^{3}\right.$ of soil) and ring (38/100 $\mathrm{cm}^{3}$ of soil) nematodes, their abundance was comparatively less than British spiral nematode $\left(351 / 100 \mathrm{~cm}^{3}\right.$ of soil) (Table 2). Even though a higher mean population density was recorded for the British spiral nematode $\left(710 / 100 \mathrm{~cm}^{3}\right.$ of soil) than spiral $(450 / 100$ $\mathrm{cm}^{3}$ of soil), ring $\left(295 / 100 \mathrm{~cm}^{3}\right.$ of soil), and dagger $\left(29 / 100 \mathrm{~cm}^{3}\right.$ of soil) nematodes (Table 2), the British spiral nematode was found associated with muscadine grapes in a single vineyard located in Grady County, GA.

We found eight PPNs including sting (Belonolaimus spp.), rootknot, ring, stunt, spiral, stubby-root, lesion, and dagger nematodes present in muscadine grape vineyards in seven NC counties (Table 1). Of these, only three including spiral, dagger, and ring nematodes occurred in the highest number of samples $(89,80$, and $76 \%$ of samples, respectively), followed by stubby-root, lesion, and root-knot nematodes in 18, 13, and $13 \%$ samples, respectively (Table 3). Among the three most frequently occurring nematodes, ring was the most abundant nematode, with mean soil population density of 93 nematodes $/ 100 \mathrm{~cm}^{3}$ of soil (Table 3).

Seven PPNs including root-knot, ring, stunt, spiral, stubby-root, lesion, and dagger nematodes were common to both GA and NC (Table 1), but their frequencies and population densities were lower in GA than in NC (Tables 2 and 3). Furthermore, the overall highest 
mean population densities were recorded for ring and spiral nematodes and the lowest for other nematodes on muscadine grapes in both GA and NC. Our findings corroborate those of Pinkerton et al. (1999) and Bird and Ransdell (1985), who showed that ring nematode frequently occurred in high population densities in western Oregon and Michigan wine grapes. Although the damage threshold level of ring nematode on muscadine is unknown, it has been reported that this nematode can cause severe damage to bunch grapes (Ferris and McKenry 1975; Santo and Bolander 1977; Zasada et al. 2012), blueberries (blueberry replant disease; Jagdale et al. 2013), and peaches (short life of peach; Nyczepir 1989). For spiral nematode, our results markedly differed with Pinkerton et al. (1999), who reported the occurrence of spiral nematode in only $3 \%$ vineyards compared with all the vineyards surveyed in the present study. Because this nematode is known to contribute stress on many other crops, it may have potential to cause severe damage to muscadine grapes.

Dagger nematodes were found at high (80\%) and low (28\%) frequencies, with the highest population densities of 28 and 17 nematodes $/ 100 \mathrm{~cm}^{3}$ of soil in $\mathrm{NC}$ and GA, respectively. It is well known that dagger nematodes are pathogenic to grapes and capable of transmitting nepoviruses that can affect grapevine growth (Hewitt et al. 1958; Nigh 1965; Ramsdell and Meyers 1974; Raski and Radewald 1958; Uyemoto 1970). Our data suggest that dagger nematode may be more common in NC than GA, and if they are infected with nepoviruses, they may be responsible for recent yield losses, because the densities recorded in the present study surpass the published population threshold level by McKenry (1992).

The root-knot nematode is considered a major nematode pest of multiple grape species (Aballay et al. 2009; Bird and Ransdell 1985; Khan et al. 2009; Téliz et al. 2007; Zasada et al. 2012), but threshold levels varied between studies and species (Anwar and McKenry 2002; McKenry 1992; Quader et al. 2002). In muscadines, we observed the maximum density of root-knot nematodes to be 3 to 5 infective juveniles/100 $\mathrm{cm}^{3}$ of soil, which is much lower than the reported population threshold level of 50 infective juveniles/100 $\mathrm{cm}^{3}$ of soil that generates yield losses in grapevines (Anwar and McKenry 2002). It is possible that muscadine grapes are a poor host

County-wise occurrence of plant-parasitic nematodes on commercial vineyards in Georgia and North Carolina
in August and October 2018, respectively
Nematode genera

\begin{tabular}{|c|c|c|c|c|}
\hline Survey 0 & rasitic nematod & $\begin{array}{l}\text { E } 2 \\
\text { mercial vin }\end{array}$ & in Georgia, Augus & \\
\hline Nematode species & Percent frequency $^{a}$ & Abundance $^{b}$ & Standard deviation & $\begin{array}{l}\text { Maximum density } \\
\text { per } 100 \mathrm{~cm}^{3} \text { of soil }\end{array}$ \\
\hline British spiral, Scutellonema spp. & 8 & 351 & 123 & 710 \\
\hline Dagger, Xiphinema spp. & 28 & 5 & 5 & 29 \\
\hline Lesion, Pratylenchus spp. & 33 & 2 & 2 & 5 \\
\hline Sheath, Hemicycliophora spp. & 3 & 5 & 1 & 5 \\
\hline Spiral, Helicotylenchus spp. & 93 & 74 & 107 & 450 \\
\hline Stubby-root, Paratrichodorus spp. & 5 & 1 & 1 & 1 \\
\hline Stunt, Tylenchorhynchus spp. & 8 & 1 & 1 & 1 \\
\hline
\end{tabular}

a Percent of total samples with species present, $N=40$ samples.

${ }^{\mathrm{b}}$ Sum of nematode densities per $100 \mathrm{~cm}^{3}$ of soil divided by the total number of samples in which the nematode genus was detected.

${ }^{\mathrm{c}}$ Maximum count observed in the samples. Minimum was zero for all species. 
for root-knot nematodes, but given its pathogenic association with other grape species, focused study is needed to verify muscadine susceptibility or resistance to root-knot nematode.

When we compared the PPN nematode community from all GA and NC muscadine soil samples simultaneously, NMS analysis yielded a three-dimensional solution (three statistically significant axes, cumulatively $57.4 \%$ of the model variance) with a final stress of 13.6 (indicating a stable ordination for an ecological community (McCune and Grace 2002). The ordination was dominated by samples from GA (red boxes) on the left, extending from the front of the ordination (larger red boxes) to the rear (smaller red boxes) (Fig. 1). The centroids (gray pyramids) for British spiral, spiral, lesion, and sheath nematodes were positioned within the cloud of GA samples (Fig. 1). On the right side of the ordination, samples from $\mathrm{NC}$ (blue boxes) predominated, also ranging from the front to the back of the ordination space. The centroids for root-knot, sting, stubby-root, stunt, ring, and dagger nematodes were nested within the samples collected from NC.

\begin{tabular}{|c|c|c|c|c|}
\hline \multicolumn{5}{|c|}{$\begin{array}{c}\text { TABLE } 3 \\
\text { Survey of plant-parasitic nematodes in commercial vineyards in North Carolina, October } 2018\end{array}$} \\
\hline Nematode species & Percent frequency ${ }^{a}$ & Abundance ${ }^{\mathbf{b}}$ & Standard deviation & $\begin{array}{l}\text { Maximum density } \\
\text { per } 100 \mathrm{~cm}^{3} \text { of soil }\end{array}$ \\
\hline Dagger, Xiphinema spp. & 80 & 4 & 4 & 17 \\
\hline Lesion, Pratylenchus spp. & 13 & 2 & 1 & 4 \\
\hline Ring, Mesocriconema spp. & 76 & 93 & 139 & 844 \\
\hline Sting, Belonolaimus spp. & 9 & 1 & 1 & 1 \\
\hline Stubby-root, Paratrichodorus spp. & 18 & 2 & 2 & 10 \\
\hline Stunt, Tylenchorhynchus spp. & 40 & 9 & 11 & 66 \\
\hline
\end{tabular}

${ }^{\text {a }}$ Percent of total samples with genus present, $N=55$ samples.

${ }^{\mathrm{b}}$ Sum of nematode densities per $100 \mathrm{~cm}^{3}$ of soil divided by the total number of samples in which the nematode genus was detected.

${ }^{\mathrm{c}}$ Maximum count observed in the samples. Minimum was zero for all species.

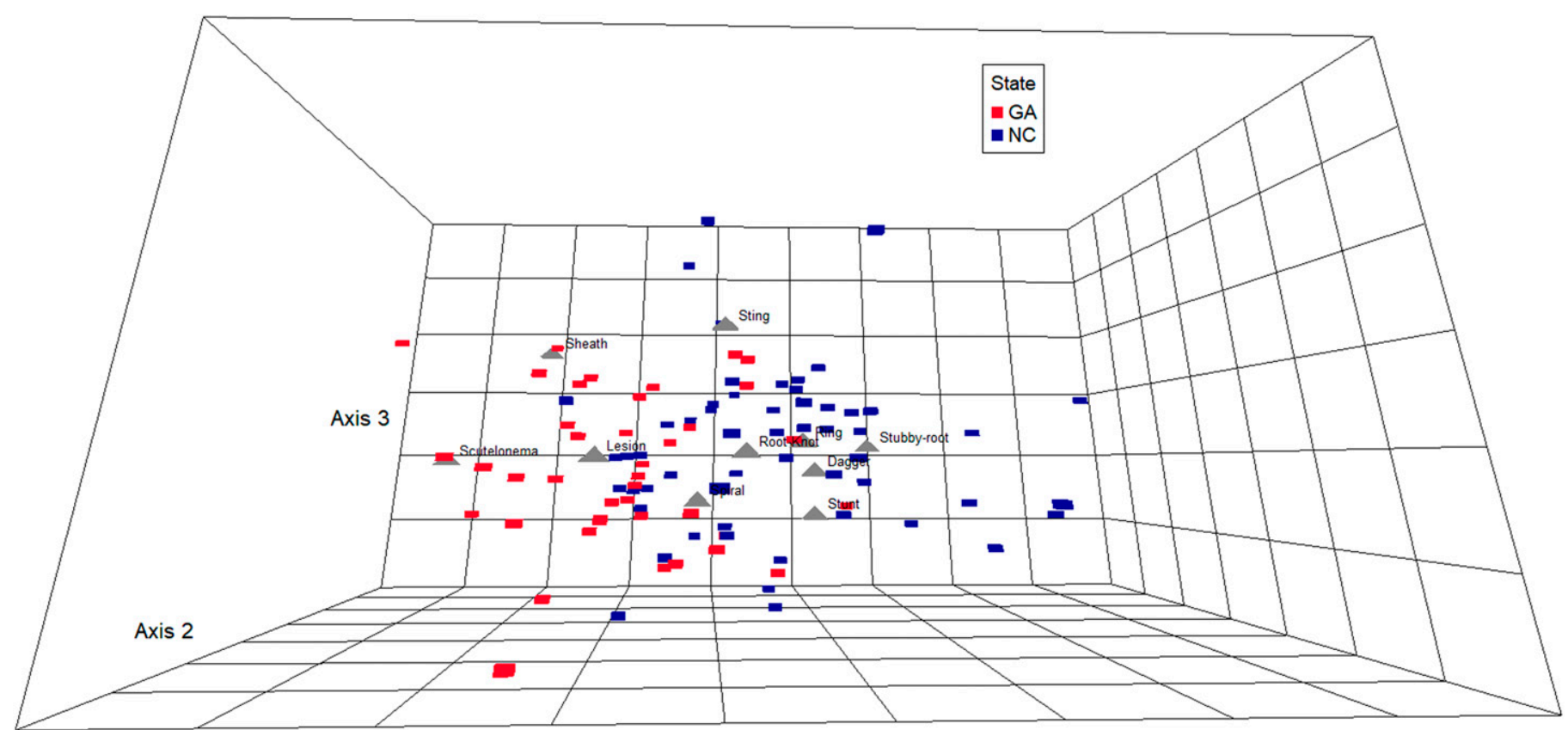

Axis 1

FIGURE 1

Nonmetric multidimensional scaling (NMS) three-dimensional solution of composite nematode samples beneath muscadine grapes in Georgia (GA, red boxes) and North Carolina (NC, blue boxes) (final NMS stress $=13.6$, Gower's distance, 250 real and randomized runs, three axes in the final solution: axis $1=$ $26.3 \%$ of model variance, $P=0.019$; axis $2=9 \%$ of model variance, $P=0.039$; and axis $3=22.1 \%$ of model variance, $P=0.039$ ). Larger sized symbols indicate positions in the front of the ordination space and become smaller as their position transitions to the back of the ordination. GA vineyard samples occur primarily on the left-hand side of the ordination and run from the front to back of the ordination. NC vineyard samples occur primarily on the right-hand side of the ordination and are similarly distributed from the front to back. The gray pyramid represents the centroid of each nematode species relative abundance among all analyzed field samples (ring = Mesocriconema spp., root-knot = Meloidogyne spp., sting = Belonolaimus spp., dagger = Xiphinema spp., stubby-root $=$ Paratrichodorus spp., stunt $=$ Tylenchorhynchus spp., spiral = Helicotylenchus spp., lesion $=$ Pratylenchus spp., sheath $=$ Hemicycliophora spp., and British spiral = Scutellonema spp.). 
Spatial separation of GA and NC samples in the NMS ordination suggested that the muscadine grape nematode communities may differ between the two states. MRPP analysis indicated that the muscadine nematode communities were highly likely to differ between GA and NC (MRPP results from Gower's distance: chance-corrected $A$ statistic $=0.0693, T=-16.5, P$ value $<$ $0.00000001)$. Indicator species analysis identified four nematode species with statistically significant $(P<0.05)$ indicator values for either GA (lesion nematode) or NC (ring, stunt, and dagger nematodes) (Table 4) muscadine grapes. Four other nematodes (sting, spiral, stubby-root, and British spiral) had $P$ values $>0.05$ and $<0.10$ (Table 4). The PPN genera without statistically significant indicator values were either not sufficiently abundant within a state's pool of samples or common enough within a state to be statistically associated with that state.

To our knowledge, we present the first systemic survey of PPNs on muscadine grapes in GA and NC. We found seven PPNs including root-knot, ring, stunt, spiral, stubby-root, lesion, and dagger nematodes in the muscadine grape rhizosphere common to both GA and NC. These same nematode genera have been also reported from bunch grapes in California (Raski et al. 1973), Idaho (Zasada et al. 2012), Michigan (Bird and Ransdell 1985), Oregon (Pinkerton et al. 1999), and Washington (Zasada et al. 2012). Three PPNs found on muscadines in GA and NC (spiral, stunt, and stubby-root nematodes) were not reported from Michigan and Washington, from California, Michigan, and Oregon, and from California and Oregon, respectively. Our survey results suggest that the muscadine and bunch grape PPN communities likely share some of the same genera. However, muscadine PPN communities in GA and NC strongly differed from each other. We do not know the cause of the betweenstate differences in the muscadine grape PPN communities, but it is possible that both biotic (predatory nematodes, nematophagous fungi, etc.) and abiotic (drought stress, physical and chemical properties of soil, temperature, etc.) factors play a role. Regardless, the between-state nematode community divergence suggests the possibility that vineyard management strategies may necessarily differ between states depending on the dominant nematodes.

\begin{tabular}{|c|c|c|c|}
\hline \multicolumn{4}{|c|}{$\begin{array}{l}\text { TABLE } 4 \\
\text { Indicator species analysis results for muscadine grape } \\
\text { nematode communities in Georgia (GA, } N=40 \text { samples) } \\
\text { and North Carolina (NC, } N=55 \text { samples) })^{a}\end{array}$} \\
\hline Nematode & $\begin{array}{l}\text { Indicator } \\
\text { group }\end{array}$ & $\begin{array}{l}\text { Indicator } \\
\text { index value }\end{array}$ & $P$ value \\
\hline Root-knot, Meloidogyne spp. & $\mathrm{NC}$ & 8.9 & 0.25 \\
\hline Sting, Belonolaimus spp. & $\mathrm{NC}$ & 9.1 & 0.07 \\
\hline Lesion, Pratylenchus spp. & GA & 24.4 & 0.012 \\
\hline $\begin{array}{l}\text { Stubby-root, Paratrichodorus } \\
\text { spp. }\end{array}$ & $\mathrm{NC}$ & 15.3 & 0.06 \\
\hline Ring, Mesocriconema spp. & $\mathrm{NC}$ & 51.8 & 0.009 \\
\hline Stunt, Tylenchorhynchus spp. & $\mathrm{NC}$ & 37.1 & 0.004 \\
\hline Spiral, Helicotylenchus spp. & GA & 52.7 & 0.06 \\
\hline Dagger, Xiphinema spp. & $\mathrm{NC}$ & 60.8 & 0.002 \\
\hline Sheath, Hemicycliophora spp. ${ }^{b}$ & GA & 2.5 & 0.43 \\
\hline British spiral, Scutellonema spp. ${ }^{\text {b }}$ & GA & 7.5 & 0.07 \\
\hline
\end{tabular}

${ }^{a}$ Indicator index value (0 to 100 ) and probability (from 5,000 randomizations) for each nematode species.

${ }^{\mathrm{b}}$ Recorded from only one field.

\section{Acknowledgments}

The authors thank the Cooperative Extension Agents from both Georgia and North Carolina for their assistance in the survey.

\section{Literature Cited}

Aballay, E., Persson, P., and Martensson, A. 2009. Plant-parasitic nematodes in Chilean vineyards. Nematropica 39:85-97.

Anwar, S. A., and McKenry, M. V. 2002. Development response of a resistancebreaking population of Meloidogyne arenaria on Vitis sp. J. Nematol. 34: 28-33.

Bird, G. W., and Ransdell, D. C. 1985. Population trends and vertical distribution of plant-parasitic nematodes associated with Vitis labrusca L. in Michigan. J. Nematol. 17:100-107.

Chen, J., Copes, W. E., Miller, R. W., and Lamikanra, O. 2001. Diseases: Nematodes. Page 206 in: Muscadine Grape. F. M. Basiouny and D. G. Himelrick, eds. ASHS Press, Alexandria, VA.

Cline, B., and Fisk, C. 2006. Overview of muscadine grape acreage, cultivars and production areas in the southeastern U.S. Muscadine Grape Workshop for Cooperative Extension Agents, 2006. The Southern Region Small Fruit Consortium. https://smallfruits.org/files/2019/06/SRFC-training-Sept-13-152006.pdf.

Cline, B., Horton, D., Hale, F., Burrack, H., Mitchem, W., Jennings, K., Lockwood, D., Fisk, C., Krewer, G., Bellinger, B., Guillebeau, P., Brannen, P., and Smith, P. 2010. 2010 Southeast Regional Muscadine Grape Integrated Management Guide. Bulletin 45. University of Georgia, Athens, GA. https:// grapes.ces.ncsu.edu/wp-content/uploads/2013/09/2010-muscadine-IMG-Draft2feb2010-_Cline_-2.pdf?fwd=no

Dufrene, M., and Legendre, P. 1997. Species assemblages and indicator species: The need for a flexible asymmetrical approach. Ecol. Monogr. 67:345-366.

Ector, B. J., Magee, J. B., Hegwood, C. P., and Coign, M. J. 1996. Resveratrol concentration in muscadine berries, juice, pomace, purees, seeds and wines. Am. J. Enol. Vitic. 47:57-62.

Ferris, H., and McKenry, M. V. 1975. Relationship of grapevine yield and growth to nematode densities. J. Nematol. 7:295-304.

Georgia Crop Reporting Service. 2000. Fruits, nuts, and vegetables. Page 51 in: Georgia Agricultural Facts. Georgia Agricultural Statistics Service, Athens, GA.

Hewitt, W. B., Raski, D. J., and Goheen, A. C. 1958. Nematode vector of soilborne fanleaf virus of grapevine. Phytopathology 48:586-595.

Jagdale, G. B., Holladay, T., Brannen, P. M., Cline, W. O., Agudelo, P., Nyczepir, A. P., and Noe, J. P. 2013. Incidence and pathogenicity of plantparasitic nematodes associated with blueberry (Vaccinium spp.) replant disease in Georgia and North Carolina. J. Nematol. 45:92-98.

Jenkins, W. R. 1964. A rapid centrifugal-flotation technique for separating nematodes from soil. Plant Dis. Rep. 48:692.

Khan, A., Bilqees, F. M., and Khatoon, N. 2009. Histopathology of grapevines roots infected with root-knot nematode Meloidogyne incognita. Pak. J. Nematol. 27:155-158.

Krewer, G., and Myers, S. 2017. Home garden muscadines. Circular 949. University of Georgia Extension, Athens, GA. https://extension.uga.edu/ publications/detail.html?number=C949\&title=Home\%20Garden\%20Muscadines.

Kruskal, J. B. 1964. Nonmetric multidimensional scaling: A numerical method. Psychometrica 29:115-129.

Lider, L. A. 1954. Inheritance of resistance to root-knot nematode (Meloidogyne incognita var. acrita Chitwood) in Vitis spp. J. Helminthol. Soc. Wash. 21: 53-60.

McCune, B., and Grace, J. B. 2002. Analysis of ecological communities. MJM Software Design, Gleneden Beach, OR.

McCune, B., and Mefford, M. J. 2016. PC-ORD: Multivariate Analysis of Ecological Data, Version 7. MjM Software Design, Gleneden Beach, OR.

McKenry, M. V. 1992. Nematodes. Pages 281-285 in: Grape Pest Management, 2nd ed. D. L. Flaherty, ed. Publication 3343. Division of Agriculture and Natural Resources, University of California, Oakland, CA.

Mielke, P. W., and Berry, K. J. 2001. Permutation Methods: A Distance Function Approach. Springer Series in Statistics. Springer, New York, NY.

Nigh, F. L., Jr. 1965. Effects of Criconemella xenoplax, Longidorus elongates and Xiphinema americanum on root development of Thompson seedless grapes. Phytopathol. 55:1070 (Abstr.).

Nyczepir, A. P., 1989. Peach tree short life: A nematode associated disease. Nematology Circular No. 163. Florida Department of Agriculture and Consumer Services, Tallahassee, FL.

Olas, B., and Wachowicz, B. 2005. Resveratrol, a phenolic antioxidant with effects on blood platelet functions. Plateles 16:251-260. 
Pastrana-Bonilla, E. Akoh, C. C., Sellappan, S., and Krewer, G. 2003. Phenolic content and antioxidant capacity of muscadine grapes. J. Agric. Food Chem. 51:5497-5503.

Percival, S. S., Sims, C. A., and Talcott, S. T. 2002. Immune benefits of consuming red muscadine wine. University of Florida, Gainesville, FL. http:// edis.ifas.ufl.edu/fs085

Pinkerton, J. N., Forge, T. A., Ivors, K. L., and Ingham, R. E. 1999. Plantparasitic nematodes associated with grapevines, Vitis vinifera, in Oregon vineyards. J. Nematol. 31:624-634.

Quader, M., Riley, I. T., and Walker, G. E. 2002. Damage threshold for Meloidogyne incognita for the establishment of grapevines. Int. J. Nematol. 12:125-130.

Ramsdell, D. C., and Meyers, R. L. 1974. Peach rosette mosaic virus, symptomology and nematodes associated with grapevine "degeneration" in Michigan. Phytopathology 64:1174-1178.

Raski, D. J. 1988. Nematode parasites of grape. Pages 55-59 in: Compendium of Grape Diseases. R. C. Pearson and A. C. Goheen, eds. American Phytopathological Society, St. Paul, MN.

Raski, D. J., Hart, W. H. and Kasimatia, A. N. 1973. Nematodes and their control in vineyards. California Agriculture Experiment Station Circular 533.
Raski, D. J., and Radewald, J. D. 1958. Reproduction of symptomology of certain ectoparasitic nematodes on roots of Thompson seedless grape. Plant Dis. Rep. 42:941-943.

Santo, G. S., and Bolander, W. J. 1977. Effects of Macroposthonia xenoplax on the growth of Concord grape. J. Nematol. 9:215-217.

Signorelli, P., and Ghidoni, R. 2005. Resveratrol as an anticancer nutrient: Molecular basis, open questions and promises. J. Nutr. Biochem. 16:449466.

Téliz, D., Landa, B. B., Rapoport, H. F., Camacho, F. P., Jimenez-Diaz, R. M., and Castillo, P. 2007. Plant parasitic nematodes infecting grapevine in southern Spain and susceptible reaction to root-knot nematodes of rootstocks reported as moderately resistant. Plant Dis. 91: 1147-1154.

U.S. Department of Agriculture (USDA). 2015. Quick Stats. 3 November 2015. https://www.nass.usda.gov/Quick_Stats/

Uyemoto, J. K. 1970. Symptomatically distinct strains of tomato ringspot virus isolated from grape and elderberry. Phytopathology 60:1838-1841.

Zasada, I. A., Riga, E., Pinkerton, J. N., Wilson, J. H., and Schreiner, R. P. 2012. Plant- parasitic nematodes associated with grapevines, Vitis vinifera, in Washington and Idaho. Am. J. Entomol. Vitic. 63:522-528. 